\title{
Influence of Family and Childhood Memories in the Development and Manifestation of Paranoid Ideation
}

\author{
Célia Barreto Carvalho, ${ }^{1,2 *}$ Carolina da Motta, ${ }^{1,2}$ José Pinto-Gouveia $^{2}$ and \\ Ermelindo Peixoto ${ }^{1}$ \\ ${ }^{1}$ Department of Educational Sciences, University of Azores, Azores, Portugal \\ ${ }^{2}$ CINEICC, Faculty of Psychology and Educational Sciences, University of Coimbra, Coimbra, Portugal
}

\begin{abstract}
Several studies point out to the influence of social experiences on perceptions of the environment and others in cognitive functioning and different aspects of psychopathology. The current study aimed at studying the influence of the psychosocial risk factors in a mixed sample of participants from the general population and affected by paranoid schizophrenia. The extent to which the existence of negative life events and events that are threatening to the inner models of the self (i.e., history of maltreatment, physical, social or psychological abuse) or the memories of these traumatic events occurring during childhood are related to the existence of paranoid beliefs in adulthood was explored. Results suggested that memories of parental behaviours characterized by antipathy from both parental figures, submissiveness and bullying victimization were important predictors of paranoid ideation in adult life. This further emphasizes the need for understanding the family and social dynamics of people presenting paranoid ideations to the development of therapeutic interventions that can effectively reduce the invalidation caused by severe psychopathology, as is the case of schizophrenia. Copyright () $2015 \mathrm{John}$ Wiley \& Sons, Ltd.

Key Practitioner Message:

- Memories of family dynamics characterized by behaviours of antipathy from both parental figures, submissiveness and bullying victimization are important predictors of paranoid ideation in adult life.

- The study highlights the importance of exploring subjective recalls of feelings and behaviours associated with early rearing experiences, peer relationships and themes related to social rank theory in the roots of internal models of relationship with the self and others in the general sample, patients diagnosed with schizophrenia and their first-degree relatives.

- Our findings indicate that schizophrenic patients in active phase differ regarding memories of threat and submission and are more likely to remember childhood experiences perceived as threatening during an active phase than when in remission.

- It is possible that by changing these internal models and social interaction styles, patients may be able to get involved in more cooperating and affiliative interactions, disconfirming these early beliefs about others being rejecting, critical or hostile towards the self, and more effectively reducing the invalidation caused by positive and negative symptomatology of schizophrenia on social functioning.
\end{abstract}

Keywords: paranoia, parental styles, schizophrenia, bullying

Several authors have researched the influence of social experiences on perceptions of the environment and others in paranoid ideation, based on the evolutionist perspective by Dixon (1998). It is acceptable, as defended by Dixon (1998), that our capacity to detect signs of threat is directly proportional to our survival skill. When exposed to

*Correspondence to: Célia Barreto Carvalho, Departamento de Ciências da Educação, Universidade dos Açores, Rua Mãe Deus, Ponta Delgada 9500-321 PONTA DELGADA, Apartado 1422, PT - 9501-801 Ponta Delgada, Açores, Portugal.

E-mail: ccarvalho@uac.pt potentially threatening situations (by others or the environment) or negative life events for a long period, individuals may easily develop persecutory ideas about others and the world. According to the interpersonal theory by Trower and Chadwick (1995), there are two types of paranoia ('poor me' and 'bad me') that can be manifested depending on the individual's construction of the self. In both cases, this deficient construction of the self leads individuals to perceive social interaction as potentially threatening and to use paranoia as a defence to this perceived social threat. Attachment theorists have long explored how early attachment experiences are fundamental to 
the construction of the dynamic internal models of the self (Bowlby, 1969; Bowlby, 1973; Bowlby, 1980). These models determine the psychological development over the lifespan and influence different interpersonal styles, with distinctive features such as anxiety and/or avoidance, or security (Collins \& Feeney, 2000). Studies based on attachment theory have focused on the implications of the absence of warm parental relations and on parenting styles that are controlling or intrusive, and research on the relationship between psychopathology and early memories of parenting in adults is based on the experiences of parental styles and behaviours such as negligence, rejection or overprotection (Schore, 2000; Schore, 2001). However, studies based on social rank theories suggest that the individual's feelings and behaviours towards the parental styles may be more important than parental behaviours itself. The relationship between parents and children is based on power. Social rank theorists emphasize the threats felt by offspring (lower rank) and submissive behaviours that are learned through these early relationships (Gilbert, Boxall, Cheung, \& Irons, 2005; Gilbert, 2000). Results from research based on attachment theory showed the influence that early attachment experiences have on social interaction styles. Troy and Sroufe (1987) proposed that children with avoidant attachment styles have an increased probability of being bullied and victimization is a common and frequent experience (Bendixen \& Olweus, 1999; Craig, 1998; Solberg \& Olweus, 2003). Current research points to the role of early life events in the development of psychopathological symptoms in adulthood. Results have shown that experiences of abuse and neglect in childhood, assessed through retrospective interviews, are predictive of psychiatric disorders in adult life, with an important role in the definition of etiological models of these disorders (Bifulco, Bernazzani, Moran, \& Jacobs, 2005). The current study investigates the influence of the aforementioned psychosocial risk factors in a mixed sample of participants from the general population and those affected by paranoid schizophrenia. The main goal is to assess the extent to which the existence of negative life events and threats to the inner models of the self (as the history of maltreatment, physical, social or psychological) or the memories of these traumatic events occurring during childhood may be related to the existence of paranoid beliefs in the general population and in a group of patients with paranoid schizophrenia. One of the goals of our study is to assess the influence of family dynamics, specifically parental antipathy and neglect, and physical and sexual abuse in childhood, in the development and manifestation of paranoid ideation in adult Q2 life. The assumption is that patients with paranoid schizophrenia (presenting more paranoid ideation) differ from unaffected individuals concerning the memories of traumatic life events (e.g., physical abuse, parental hostility and neglect). Concerning paranoid ideation, it is expected that early experiences of neglect and abuse lead to increased frequencies and severity of paranoid thoughts. It is expected that individuals presenting high scores on scales referring to memories of traumatic life events (physical abuse, antipathy or neglect from parental figures) are those who present higher scores on scales assessing the presence and intensity of paranoid ideation. This association is also expected in case of memories of threatening situations or subordination, and it is expected that paranoid ideation presents a similar relationship to those found in depression and mood disorders (Anl1 \& Karsl1, 2010; Baker \& Hoerger, 2012; Heider, Matschinger, Bernert, Alonso, \& Angermeyer, 2006; Manfredi et al., 2011; Muris, Schmidt, Lambrichs, \& Meesters, 2001; Parker, 1993; Richter, Richter, Eisemann, Seering, \& Bartsch, 1995; Yap, Pilkington, Ryan, \& Jorm, 2014). It is also expected that the experiences of being bullied by others are more frequent in individuals with schizophrenia than in their relatives and unaffected individuals.

\section{METHODS}

\section{Participants and Procedures}

The study was conducted with the approval and meeting the standards required by the ethical committee and boards from the hospitals and institutions in S. Miguel Island (Azores) and Funchal (Madeira). Study goals and the methods used in the current research were explained, and informed consent was obtained prior to participation. Participation was voluntary and consisted of filling a set of self-report instruments. Data confidentiality and anonymity were observed at all times. In the case of participants suffering from paranoid schizophrenia, senior psychologists were available to aid in the proper filling of the questionnaire in case of reading or comprehension difficulties. One of the psychologists was also present to aid participants from the remaining groups in case they presented any difficulties.

Participants were distributed across four different groups: participants in an active paranoid schizophrenia phase, individuals with paranoid schizophrenia currently in remission, patients' relatives and participants from the general population.

\section{Statistical Analysis}

Statistical analysis was carried out using SPSS v. 16.0 (SPSS Inc, Chicago, Illinois, USA) Correlation analysis, independent sample $t$-tests and multiple analysis of covariance were used to assess the associations or compute group comparisons across different measures. Tukey and pairwise post hoc tests were calculated when results from analysis of variance and covariance were statistically significant. Chi- 
square tests were used to study the differences in distribution scores from paranoia scales between groups.

\section{Measures}

General Paranoia Scale (GPS; Fenigstein \& Vanable, 1992; Portuguese version by Lopes, 2010) is a widely used selfreport scale assessing paranoid ideation in non-clinical populations. It encompasses beliefs concerning influence and malevolence from others. These beliefs may take the form of mistrust and suspicion of others' intentions, negative judgments about the self or even persecutory ideas. The 20 items are scored on a 5-point Likert-type scale (from $1=$ 'completely disagree' to $5=$ 'completely agree'), and total scores may vary between 20 and 100, with higher scores indicating more paranoid ideation. Internal consistencies in the original studies by Fenigstein and Vanable (1992) presented good reliability in four different samples, ranging between 0.78 and 0.89 . In the current study, internal consistency was very good $(\alpha=0.92)$.

Paranoia Checklist (PC; Freeman et al., 2005; Portuguese version by Lopes, 2010) was designed to assess paranoid thoughts with more clinical relevance than those assessed by the GPS and to allow a multidimensional evaluation of paranoid ideation. This checklist comprises 18 items for each dimension (frequency, degree of conviction and distress caused by paranoid thoughts). Items are answered in a 5-point Likert-type scale, on a continuum: $1=$ 'rarely' $^{\prime}$ to $5=$ 'at least once a week' for the frequency dimension, $1=$ 'I do not believe it' to $5=$ 'I totally believe it' for the conviction dimension and $1=$ 'no distress' to $5=$ 'it causes me a lot of distress' for the distress dimension. The authors have validated the PC in a large non-clinical sample $(n=1202)$, obtaining very good internal consistency for each dimension (all above 0.90). In the current study, Cronbach's alpha coefficient presented similar results, also above 0.90 in the three dimensions of the scale.

Beck's Depressive Inventory (BDI; Beck, Ward, Mendelson, Mock, \& Erbaugh, 1961; Portuguese version by Vaz-Serra \& Pio Abreu, 1973) assesses depressive symptomatology, organized in six types of symptoms: affective, cognitive, motivational, delusional, physical and functional (sleep, appetite, weight and libido). It comprises 27 sets of statements related to depressive symptoms, ordered by severity (non-existent, mild, moderate and severe). Studies indicate that the BDI is a valid and reliable instrument

Q4|Q3 (Beck \& Beasmesderfer, 1974 cit. in Pinto-Gouveia, 1990). Kendall, Hollon, Beck, Hammen, and Ingram (1987) have proposed several cutoff points for BDI scores: $0-9=$ individuals are considered to be healthy; $10-20=$ mild depression, in which scores 10-17 represent dysphoric states and scores above 17 represent depressive states; $20-30=$ moderate depression; and above $30=$ severe depression. Validation studies in the Portuguese population propose a cutoff point of 12 to distinguish between depressed and non-depressed individuals. Internal consistency for BDI found in the current sample was of 0.90 .

Early Life Experiences Scale (ELES; Gilbert, Cheung, Grandfield, Campey, \& Irons, 2003; Portuguese version by Lopes \& Pinto-Gouveia, 2005) is a questionnaire designed Q5 to assess childhood memories, concerning experiences of perception of threat and subordination. The scale comprises 15 items: six items referring to the perceptions of threat and nine items referring to feelings of subordination and submissive behaviours, answered with a 5-point Likert scale on the frequency and veracity of statements depicting childhood memories $(1=$ 'completely false' to $5=$ 'completely true'). Internal consistency was very good in the original studies by Gilbert et al. (2003), ranging between 0.85 and 0.89 . In the current sample, internal consistency ranged between 0.77 and 0.81 for the subscales and total scale.

Childhood Experiences of Care and Abuse Questionnaire (CECA-Q; Bifulco et al., 2005; Portuguese version by Carvalho et al., 2006) is a questionnaire devised to col- Q6 lect information on family dynamics and parental abandonment during childhood and to identify the parental figures that were most significant during development (before the age of 17 years). This questionnaire is composed of screening questions for sexual and physical abuse, and neglect and antipathy scales scored separately for each parent (e.g., mother and father).

The Antipathy and Neglect Scales comprise eight items related to antipathy (coldness, criticism, rejection or hostility towards the child) from the parent (e.g., he/she was critical towards me) and eight relating to neglect (e.g., he/she was interested in my problems). All items are repeated for each parental figure and answered in a 5-point Likert-type scale $(1=$ 'not at all' to $5=$ 'totally'). Bifulco et al. (2005) state that the CECA-Q is a good screening tool for studying the relationships between the adverse experiences during childhood and the development of psychopathology. In the current study, internal consistencies ranged between 0.78 (mother's antipathy) and 0.88 (neglect from father).

Bully/Victim Questionnaire (BVQ; Olweus, 1989; Q7 Portuguese version by Lopes \& Pinto-Gouveia, 2005) is a Q8 questionnaire assessing the perceptions of being bullied and victimized by others during childhood. The questionnaire presents a definition of bullying, and the following questions explore the characteristics of bullying (e.g., where it took place and the number of perpetrators). Next, several items are answered in a 5-point Likert-type scale $(1=$ 'never occurs' to $5=$ 'it occurs several times a week'). The total score is an indicator of the severity of the bullying, allowing the characterization of bullying as physical, verbal or indirect. The BVQ presented good internal consistency for the sample in the current study, with 0.68 for the total scale, 0.80 for the indirect bullying and 0.60 for the remaining dimensions (physical and verbal bullying). 


\section{RESULTS}

\section{Sample Characteristics}

The sample in this study consisted of 187 participants. Participants diagnosed with paranoid schizophrenia were divided in three subsamples: Azorean patients in remission, Azorean patients in active phase and Madeira island patients in active phase. The Madeira patients were distinct from the other groups because it comprised female particT1 ipants only (Table 1). Because of the nature of the samples in this study (clinical and non-clinical), some differences in sociodemographic variables are expected. The healthy control group differed from the clinical groups in terms of years of education and age, where participants from the general population had completed more years in school and patients' relatives were older than the remaining groups. In addition, the participants from the general population also presented a higher socioeconomic status than the remaining groups, whilst participants in the clinical groups presented higher percentages of single people in comparison with the non-clinical groups. Despite these differences, there were no significant correlations between the variables investigated (scales and subscales) and sociodemographic variables. Concerning the groups of patients in active phase from Madeira and Azores, independent sample $t$-tests showed that both groups differed solely on the bullying variable $(t=2.67 ; p=0.011)$. For this reason, these patients were grouped together in further analyses, except for in the analysis on bullying experiences.

\section{Parental Styles and Memories of Threat and Submission}

During Childhood and Their Influence on Paranoid Ideation in Adult Life

Correlation analysis showed the significant and positive associations between BDI scores and ELES and all subscales and total CECA-Q scores (ranging from $r=0.146$ to $r=0.335)$. All correlations between CECA-Q scores and paranoia measures (PC and GPS) were significant and positive. Thus, considering the moderate correlations between neglect and antipathy dimensions and paranoia, the relative contributions of these variables were analysed.

Regarding depression, both patient groups significantly differ on BDI scores $(\mathrm{M}=20.1, S D=10.9$; $\mathrm{M}=14.7$, $S D=10.1), t=2.25, p=0.028$, and this variable is correlated with the variables in this study. For this reason, depression was included as a covariate in subsequent analysis.

Analysis of covariance (including BDI scores on depression as a covariate) showed that the mean scores of CECA-Q factors (neglect and antipathy) did not differ significantly between groups, but samples differed significantly concerning the variables of ELES (Table 2).

Because paranoia is considered to be distributed across a continuum in the population, a dimensional approach was used, and multiple regression analysis was performed

Table 1. Sample characteristics

\begin{tabular}{|c|c|c|c|c|c|c|c|}
\hline & \multicolumn{2}{|c|}{ Non-clinical population } & \multicolumn{3}{|c|}{ Clinical population } & \multirow[b]{3}{*}{$X^{2}$} & \multirow[b]{3}{*}{$p$} \\
\hline & \multirow[b]{2}{*}{$\begin{array}{c}\begin{array}{c}\text { General } \\
\text { population } \\
(n=64) \\
N(\%)\end{array}\end{array}$} & \multirow[b]{2}{*}{$\begin{array}{c}\text { Patients' } \\
\text { relatives } \\
(n=32) \\
N(\%)\end{array}$} & \multicolumn{2}{|c|}{ Azores islands } & \multirow{2}{*}{$\begin{array}{c}\text { Madeira islands } \\
\text { Active } \\
\text { schizophrenia } \\
(n=30) \\
N(\%)\end{array}$} & & \\
\hline & & & $\begin{array}{c}\text { Active } \\
\text { schizophrenia } \\
(n=31) \\
N(\%)\end{array}$ & $\begin{array}{c}\text { Patients } \\
\text { in remission } \\
\begin{array}{c}(n=30) \\
N(\%)\end{array}\end{array}$ & & & \\
\hline \multicolumn{8}{|l|}{ Gender } \\
\hline Male & $43(67.2)$ & $8(25.0)$ & $20(64.5)$ & $24(80)$ & $0(0)$ & 58.94 & 0.0001 \\
\hline Female & $21(32.8)$ & $24(75.0)$ & $11(35.5)$ & $6(20)$ & $30(100)$ & & \\
\hline Single & $18(30.0)$ & $0(0.0)$ & $21(70)$ & $21(70)$ & $12(41.4)$ & 70.8 & 0.0001 \\
\hline Married & $35(58.3)$ & $28(90.3)$ & 4(13.3) & $6(20)$ & $9(31)$ & & \\
\hline Divorced & $3(5.0)$ & $0(0)$ & $3(10)$ & $2(6.7)$ & $4(13.8)$ & & \\
\hline Widowed & $3(5.0)$ & $3(9.7)$ & 1(3.3) & $1(3.3)$ & $3(10.3)$ & & \\
\hline Civil union & $0(0)$ & $0(0)$ & $0(0)$ & $0(0)$ & $1(3.4)$ & & \\
\hline \multicolumn{8}{|l|}{ SES } \\
\hline Low & $22(37.3)$ & $15(62.5)$ & $21(75)$ & $27(90)$ & $25(86.2)$ & 46.6 & 0.0001 \\
\hline Medium & $20(33.9)$ & 4 (16.7) & 7 (25) & $3(10)$ & $4(13.8)$ & & \\
\hline High & $12(20.3)$ & $5(20.8)$ & $0(0)$ & $0(0)$ & $0(0)$ & & \\
\hline \multirow[t]{2}{*}{ Students } & $5(8.5)$ & $0(0)$ & $0(0)$ & $0(0)$ & $0(0)$ & & \\
\hline & $\mathrm{M}(S D)$ & $\mathrm{M}(S D)$ & $\mathrm{M}(S D)$ & $\mathrm{M}(S D)$ & $\mathrm{M}(S D)$ & $F$ & $p$ \\
\hline Age (in years) & $45.2(17.3)$ & $55.6(13.0)$ & $41.5(13.0)$ & $43.5(12.6)$ & $46.5(11.8)$ & 4.53 & 0.002 \\
\hline Years of education & $9.8(4.8)$ & $7.7(4.3)$ & $6.6(3.2)$ & $6.3(3.4)$ & $6.2(3.9)$ & 6.16 & 0.000 \\
\hline
\end{tabular}

SES = socioeconomic status. 
Table 2. Multiple analysis of covariance comparing Childhood Experiences of Care and Abuse and Early Life Experiences Scale scores between groups

\begin{tabular}{|c|c|c|c|c|c|c|}
\hline & $\begin{array}{c}\text { General } \\
\text { population }(n=62)\end{array}$ & $\begin{array}{c}\text { Patients-active } \\
\text { phase }(n=61)\end{array}$ & $\begin{array}{l}\text { Patients-in } \\
\text { remission }(n=30)\end{array}$ & $\begin{array}{l}\text { Relatives } \\
(n=30)\end{array}$ & $F(3 ; 178)$ & $p$ \\
\hline \multicolumn{7}{|c|}{ CECA-Q } \\
\hline \multicolumn{7}{|c|}{ Antipathy mother } \\
\hline $\mathrm{M}$ & 14.25 & 16.59 & 15.36 & 14.27 & \multirow[t]{2}{*}{0.763} & \multirow[t]{2}{*}{0.516} \\
\hline CI $95 \%$ & $13.20 / 16.08$ & $14.65 / 17.63$ & $13.13 / 14.15$ & $12.59 / 16.51$ & & \\
\hline \multicolumn{7}{|c|}{ Antipathy father } \\
\hline M & 15.29 & 18.37 & 15.00 & 16.30 & \multirow[t]{2}{*}{1.461} & \multirow[t]{2}{*}{0.227} \\
\hline CI $95 \%$ & $14.56 / 17.82$ & $15.64 / 19.02$ & $12.21 / 16.78$ & $14.73 / 19.18$ & & \\
\hline \multicolumn{7}{|c|}{ Neglect mother } \\
\hline M & 13.60 & 14.69 & 13.33 & 14.22 & \multirow[t]{2}{*}{0.379} & \multirow[t]{2}{*}{0.768} \\
\hline CI $95 \%$ & $12.57 / 15.47$ & $12.70 / 15.71$ & $11.06 / 15.13$ & $12.55 / 16.51$ & & \\
\hline \multicolumn{7}{|c|}{ Neglect father } \\
\hline $\mathrm{M}$ & 15.39 & 17.87 & 15.15 & 18.84 & \multirow[t]{2}{*}{2.520} & \multirow[t]{2}{*}{0.059} \\
\hline CI $95 \%$ & $14.44 / 18.51$ & $14.89 / 18.74$ & $12.04 / 17.2$ & $16.98 / 22.04$ & & \\
\hline \multicolumn{7}{|l|}{ ELES total } \\
\hline $\mathrm{M}$ & 34.34 & 42.28 & 36.94 & 37.03 & \multirow[t]{2}{*}{6.114} & \multirow[t]{2}{*}{0.001} \\
\hline CI $95 \%$ & $31.85 / 36.83$ & $39.74 / 44.82$ & $33.51 / 40.37$ & $33.57 / 40.48$ & & \\
\hline \multicolumn{7}{|l|}{ Threat } \\
\hline $\mathrm{M}$ & 13.26 & 16.73 & 12.69 & 14.54 & \multirow[t]{2}{*}{4.629} & \multirow[t]{2}{*}{0.004} \\
\hline CI $95 \%$ & $11.77 / 14.75$ & $15.21 / 18.25$ & $10.64 / 14.74$ & $12.48 / 16.61$ & & \\
\hline \multicolumn{7}{|c|}{ Submission } \\
\hline $\mathrm{M}$ & 11.74 & 15.42 & 12.68 & 12.24 & \multirow[t]{2}{*}{5.771} & \multirow[t]{2}{*}{0.001} \\
\hline CI $95 \%$ & $10.50 / 12.98$ & $14.16 / 16.69$ & $10.97 / 14.38$ & $10.52 / 13.96$ & & \\
\hline
\end{tabular}

Covariate value: Beck's Depressive Inventory $=11.80$.

$\mathrm{CECA}-\mathrm{Q}=$ Childhood Experiences of Care and Abuse Questionnaire. ELES, Early Life Experiences Scale. CI = confidence interval.

for the total sample $(n=187)$. The first block comprised relevant predictor variables (CECA-Q antipathy and neglect dimensions from both parents) to the dependent variable (GPS and PC). This model explained $26.3 \%\left(R^{2}=0.263\right)$ of the total variance of the GPS $\left(F_{(4,182)}=16.204, p=0.000\right)$. Standardized regression coefficients (beta values) showed that antipathy from the father is the strongest predictor of paranoia $(\beta=0.400, p=0.008)$, followed by mother's antipathy on GPS scores $(\beta=0.242, p=0.006)$. Similar results were obtained from the frequency of paranoid ideation assessed by the PC, in which multiple regression functions explain $24.8 \%\left(R^{2}=0.248\right)$ of the total variance of the scale $\left(F_{(4,182)}=14.965, p=0.000\right)$. Father's antipathy $(\beta=0.406$, $p=0.001)$ and mother's antipathy $(\beta=0.205, p=0.021)$ were also significant predictors of the frequency of paranoid ideations assessed by the PC.

Concerning the degree of conviction in those paranoid thoughts, regression analysis showed that $16.2 \%\left(R^{2}=\right.$ 0.162 ) of the total variance is explained by the CECA-Q factors $\left(F_{(4,182)}=8.768, p=0.000\right)$. In this model, only antipathy from father was a significant predictor of conviction on paranoid ideations $(\beta=0.321, p=0.002)$.

Lastly, $14.4 \%\left(R^{2}=0.144\right)$ of the total variance in the degree of distress endorsed by participants at the occurrence of paranoid ideations $\left(F_{(4,182)}=7.659, p=0.000\right)$ was explained by the CECA-Q variables. In this analysis, the antipathy from the mother was the strongest predictor of the distress caused by paranoid ideation $(\beta=0.280, p=$ $0.002)$, followed by father's antipathy $(\beta=0.218, p=0.041)$.

In order to understand the relationship between paranoid ideation (assessed with GPS and PC) and memories of perceptions of threat and submissiveness in childhood (ELES), Pearson correlation coefficients were computed between those variables before carrying out multiple regression analysis. Moderate positive correlations were found between PC dimensions and GPS scores and submission, ranging between $r=0.401, p=0.000$ and $r=0.460$, $p=0.000$; threat, ranging between $r=0.269, p=0.000$ and $r=0.388, p=0.000$; and the total ELES scale, ranging between $r=0.335, p=0.000$ and $r=0.389, p=0.000$. In a first regression model, the total ELES scores were entered as a single predictor of paranoid ideation. The regression function including the total ELES scores explained $12.9 \%\left(R^{2}=\right.$ $\left.0.129 ; F_{(1,185)}=27.473, p=0.000\right)$ of the total variance in GPS scores. Positive standardized beta $(\beta=0.360, p=0.000)$ indicates that memories of perceived threat and submission in childhood may significantly predict paranoid ideation in adult life. Similar results were found concerning the dimensions of PC as dependent variables. Regarding the PC, ELES total explained $15.1 \%$ of the total variance of the frequency of paranoid ideations $\left(R^{2}=0.151 ; F_{(1,185)}=33.01\right.$, $p=0.000), 12.8 \%$ of the total variance of the conviction on paranoid thoughts $\left(R^{2}=0.128 ; F_{(1,185)}=27.18, p=0.000\right)$ and $11.2 \%$ of the distress caused by paranoid ideation 
$\left(R^{2}=0.112 ; \quad F_{(1,185)}=23.38, p=0.000\right)$. Standardized beta values indicate that the total ELES scores are a significant predictor of the dimensions assessed by PC $(\beta=0.389, p=$ 0.000 for frequency, $\beta=0.535, p=0.000$ for conviction and $\beta=0.335, p=0.000$ for the distress caused by paranoid ideation), suggesting that paranoid ideation in adult life can be more present as more memories relating to experiences of threat and submission in childhood are recalled.

Multiple regression analysis including the threat and submission factors of ELES explained 19\% of the total variance in paranoia assessed by GPS $\left(F_{(1,185)}=27.186, p=\right.$ $0.000)$. Curiously, only memories relating to submissiveness emerged as a significant predictor of general paranoia $(\beta=$ $0.400, p=0.000)$ in adulthood. These results were similar to the paranoid ideation assessed by PC. Submissiveness was the significant predictor for models including frequency $\left(R^{2}=0.216 ; \quad F_{(2,184)}=25.35, p=0.000, \quad \beta_{\text {submissiveness }}=0.385\right.$, $p=0.000)$, conviction $\left(R^{2}=0.164 ; F_{(2,184)}=18.10, p=0.000\right.$, $\left.\beta_{\text {submissiveness }}=0.432, p=0.004\right)$ and distress $\left(R^{2}=0.163\right.$; $\left.F_{(2,184)}=17.95, \quad p=0.000, \quad \beta_{\text {submissiveness }}=0.453, \quad p=0.000\right)$ caused by paranoid thoughts. Overall, results indicate that recall of threat does not add explanatory value to paranoia but the recall of submissiveness during childhood is the main predictor of frequency, conviction and distress caused by paranoid thoughts.

\section{Bullying Experiences and Paranoia}

In addition to family dynamics and childhood memories, experiences of bullying over the lifespan were studied, both concerning victimization and perpetrating physical, verbal or indirect bullying. No statistically significant differences were found between the samples in this T3 study (Table 3). All correlations between the BVQ scores and the paranoia measures were positive and significant, ranging from $r=0.286, p=0.000$ for GPS and $r=0.370, p=$ 0.000 for the frequency of paranoid thoughts (PC) and total
BVQ scores. Linear regression analysis showed that the total score of the BVQ predicted $8.2 \%\left(R^{2}=0.082 ; F_{(1,185)}=\right.$ $16.487, p=0.000$ ) of the total variance of paranoia (GPS). Similar findings were obtained for the PC subscales (frequency, $R^{2}=0.137 ; F_{(1,185)}=17.74, p=0.000$; conviction, $\left.R^{2}=0.088 ; \quad F_{(1,185)}=21.70, p=0.000\right)$ and distress $\left(R^{2}=\right.$ $\left.0.105 ; F_{(1,185)}=21.70, p=0.000\right)$, indicating that experiences of bullying victimization can increase the frequency, conviction and distress in adulthood.

Further, multiple regression analysis was calculated to investigate the differences in the predictive ability of types of bullying (physical, verbal and indirect). The regression function explained $9.8 \%$ of the total variance of GPS $\left(R^{2}=0.098 ; F_{(3,183)}=6.64, p=0.000\right)$. Standardized regression coefficient showed that only indirect bullying was a significant predictor of paranoia $(\beta=0.272, p=0.031)$. These results were different for the paranoid ideation assessed by PC. The different forms of bullying considered individually did not present significant predictor effects in models including frequency $\left(R^{2}=0.138 ; F_{(3,183)}=9.74, p=\right.$ $0.000)$, conviction $\left(R^{2}=0.089 ; F_{(3,183)}=5.94, p=0.001\right)$ and distress $\left(R^{2}=0.105 ; F_{(3,183)}=7.14, p=0.000\right)$ caused by paranoid thoughts. Overall, results indicate that the different natures of bullying experiences do not add explicative value to paranoia. However, it is important to highlight that most participants $(74.3 \%)$ did not endorse having experienced bullying in the past.

\section{DISCUSSION}

Parent-child relationships can be regarded as relationships of power, according to social rank theory. As suggested by Gilbert and colleagues (Gilbert et al., 2003; Gilbert, 2000; Gilbert, 2002; Irons \& Gilbert, 2005), threatening environments can stimulate children to develop avoidant and submissive coping strategies to stressful situations as a

Table 3. Multiple analysis of covariance comparing Bully/Victim Questionnaire scores between groups

\begin{tabular}{|c|c|c|c|c|c|c|}
\hline & $\begin{array}{c}\text { General } \\
\text { population }(n=62)\end{array}$ & $\begin{array}{l}\text { Patients-active } \\
\text { phase }(n=61)\end{array}$ & $\begin{array}{l}\text { Patients-in } \\
\text { remission }(n=30)\end{array}$ & $\begin{array}{l}\text { Relatives } \\
(n=30)\end{array}$ & $F(3 ; 178)$ & $p$ \\
\hline \multicolumn{7}{|l|}{ BVQ total } \\
\hline $\mathrm{M}$ & 13.88 & 15.56 & 16.01 & 14.13 & 1.20 & 0.310 \\
\hline \multirow{2}{*}{\multicolumn{7}{|c|}{ Physical }} \\
\hline & & & & & & \\
\hline M & 4.32 & 5.00 & 4.82 & 4.50 & 1.49 & 0.217 \\
\hline CI 95\% & $3.88 / 4.76$ & $4.55 / 5.45$ & $4.21 / 5.42$ & $3.89 / 5.11$ & & \\
\hline \multicolumn{7}{|l|}{ Verbal } \\
\hline M & 3.78 & 4.01 & 4.30 & 3.87 & 0.446 & 0.720 \\
\hline CI 95\% & $3.25 / 4.30$ & $3.48 / 4.55$ & $3.58 / 5.03$ & $3.14 / 4.60$ & & \\
\hline \multicolumn{7}{|l|}{ Indirect } \\
\hline M & 4.73 & 5.26 & 5.67 & 4.69 & 1.10 & 0.350 \\
\hline CI 95\% & $4.07 / 5.39$ & $4.59 / 5.94$ & $4.76 / 6.57$ & $3.77 / 5.60$ & & \\
\hline
\end{tabular}

Covariate: Beck's Depressive Inventory $=11.80$.

$\mathrm{BVQ}=$ Bully/Victim Questionnaire. $\mathrm{CI}$ = confidence interval. 
defence from others and become focused on their power to harm, humiliate or reject them. These experiences render them more prone to focusing on social rank and their status and particularly vulnerable to engaging in competitive dynamics in which one must 'win' or 'dominate' another in order to assert their social status. In addition, children also become more worried with rejection and relative superiority /inferiority and can more easily trigger defensive behaviours of submission, avoidance or aggressive control.

Thus, because most human anxieties are related to what others may do to us (hostile intentions or who are more powerful), the contribution of perceptions of submission (when parental styles are dominated by criticism and hostility) in childhood to later-life paranoia becomes more clear, whether in clinical (delusions) or subclinical manifestations. Moreover, these internal models of the social world are carried to peer groups, and functioning in these groups may reinforce those strategies.

Overall, the study of the relationship between life events and paranoid ideation shows that memories of family dynamics characterized by behaviours of antipathy from both parental figures, submissiveness and bullying victimization (although less expressive) are important predictors of paranoid ideation in adult life, influencing not only the frequency but also the degree of conviction and distress felt at the occurrence of paranoid thoughts.

Memories relating predominantly to antipathy or neglectful parental styles showed no significant differences in the four samples, suggesting that responses by patients in active phases about family dynamics during childhood did not derive from delusional activities. The results seemed to show that memories of coldness, demandingness and criticism (antipathy) from parents were more related to later development of paranoid ideation than experiences of neglect. These outcomes are congruous with the current literature, which proposes that rearing experiences based on criticism and dominance do not provide a nurturing environment for the child, which are common indicators of poor attachment, marked by ambivalence and insecurity (Ainsworth, Blehar, Waters, \& Wall, 1978). These forms of attachment may support the development of internal models of insecurity and inferiority, in which others are seen as unavailable or hostile and that the self is seen as incapable and undesirable (Mikulincer, Birnbaum, Woddis, \& Nachmias, 2000). Moreover, these internal models and perceptions of the self may lead individuals to perceive social interactions as potentially threatening and to resort to paranoia as a defence to this threat (Trower \& Chadwick, 1995). In addition, Mills, Gilbert, Bellew, McEwan, and Gale (2007) demonstrated that paranoid beliefs are associated with a self-critical and hateful experience of the self.

Concerning the influence of the perception of threat and submission during childhood, results indicate that the patients in active phase differ from the participants in the remaining samples: from the patients in remission regarding memories of threat, from the relatives' sample on the memories of submission and from the general population in all dimensions evaluated by ELES. The non-significant differences between patients in remission and in active phases on submission suggest that perceptions of threat were not totally induced by paranoid schizophrenia symptomatology, since they are maintained after treatment. This was not observed regarding memories of perceptions of threats. However, this distinction may be caused by memories induced by paranoia. Paranoid beliefs are conceptualized as derived from perceptions of threats (Freeman et al., 2005), and thus, a defence mechanism encompassed in social defences against threats from organisms of the same species (Gilbert, 1992; Gilbert, 1998; Gilbert et al., 2001). Gilbert (2010) suggested that, once the threat system becomes active, thoughts arise in the form of a 'better safe than sorry' approach to social interactions, because it is safer to assume that a situation may be threatening to the individual than failing to identify actual threats. When taking into consideration that autobiographical memories (the recovery process of a past event that contributed to an individual's sense of self) can be biassed by emotional disorders (Williams et al., 2007), it is possible to conclude that patients diagnosed with schizophrenia are more likely to remember childhood experiences perceived as threatening during an active phase than when in remission.

In addition, results showed that, despite the fact that the total score of early memories of submission and threat is predictive of paranoia, only submission was a significant predictor in the explanation of paranoid ideation, associated with higher frequency, conviction and distress of these ideations in adult life. These results are also congruous with studies on depression (Hart, Gunnar, \& Cicchetti, 1996) and mood disorders (Parker, 1993; Perris, 1988; Richter et al., 1995; Rutter et al., 1997).

All dimensions of bullying were associated with paranoia, but only the total bullying score was a significant predictor of paranoia later in life. This may be due to the fact that only $25.7 \%$ of participants have reported such memories/experiences. Individuals that were actually bullied or victimized have their beliefs that others are a source of threat reinforced. In such cases, anxiety and worry concerning others can be adaptive and activate defence mechanisms related to more primitive social anxieties that have evolved in order to detect and cope with social threats (Birchwood et al., 2007; Gilbert, 2001; Gilbert et al., 2001; Trower \& Gilbert, 1989). The activa- Q10 tion of those defences can, in turn, trigger memories of situations in which one was submissive, and to parental styles dominated by antipathy, can give rise to paranoid ideations.

Overall, results are congruous with similar studies (Dagnan, Trower, \& Gilbert, 2002; Gilbert, 2001; Gilbert et al., 2001; Trower \& Gilbert, 1989), although studies of 
this nature are still scarce (Campbell \& Morrison, 2007). To the best of our knowledge, this is the first study encompassing the four populations and the first of this kind in the Portuguese population. The implications of the current findings for clinical practice relate to the importance of exploring subjective recalls of feelings and behaviours associated with early rearing experiences, peer relationships and themes related to social rank theory (Benn, Harvey, Gilbert, \& Irons, 2005) in the roots of internal models of relationship with the self and others in later life. The relationship between the parental behaviours and the child's affective experience is complex and may reflect interactions between parent's personality and child's temperament (Collins \& Feeney, 2000). Nevertheless, individuals who grew up with a perceived need for constant attention to threat (instead of warm relationships that are a source of safeness and emotion regulation as in secure attachment styles) become more vulnerable to psychological problems, namely affective disorders (Gilbert et al., 2003). This also aids clinicians to make sense of depression being significantly associated with low self-esteem, criticism from others and feelings of personal defeat. Subjective feelings of personal defeat and entrapment that may stem from these early experiences are not only associated with anhedonia and feelings of inferiority but also associated with depressive symptomatology of patients with paranoid schizophrenia (Birchwood et al., 2004; Gilbert, Allan, Brough, Melley, \& Miles, 2002). It is also important to emphasize that these perceptions of threat and defeat may not be necessarily related to overt or direct interpersonal conflict but are related to perceptions of failure or lack of capacity to achieve relevant social goals or resources in life (e.g., care eliciting, safeness, supportive relationships, sexual partners and material resources) (Gilbert, 2006; Irons, Gilbert, Baldwin, Baccus, \& Palmer, 2006; Morriss, 2000). Thus, these subjective recalls help shape internal models and social interaction styles, which are used in different social environments (i.e., peer groups) in a way that may reinforce certain defensive strategies that were effective in previous interactions (e.g., anxious and submissive individuals are less attractive and desired by their peer group, further confirming the belief that others are rejecting or hostile). It is possible that by targeting intervention on changing these internal models and social interaction styles, patients may be able to get involved in more cooperating and affiliative interactions, disconfirming these early beliefs about others being rejecting, critical or hostile towards the self.

The current study is not free from limitations, as the small convenience samples hinder result generalizability. In addition, the cross-sectional design requires further studies to corroborate these findings. By providing evidence on the influence of life trajectories and social-cognitive variables in the development and maintenance of paranoid ideation, current results highlight the need for understanding the family and social dynamics of people presenting paranoid ideations and in devising focused intervention targeting dysfunctional internal relationship models that stem from early attachment. These are important factors to take into consideration when conducting psychotherapeutic strategies to reduce paranoid ideation, a main symptom presented by patients diagnosed with schizophrenia. By understanding that these patients have a different coping style with paranoid ideation than people without psychopathology (Barreto Carvalho, da Motta, Pinto-Gouveia, \& Bernardo Peixoto, 2014), these results also emphasize the importance of changing how people cope with paranoid ideation. This aspect becomes even more significant when it refers to a positive symptom that many patients (approximately $25 \%$ ) still present when administered with antipsychotic medication (Chadwick, Birchwood, \& Trower, 1996).

Thus, understanding these mechanisms can be fundamental to the development of therapeutic interventions that can help tackle these issues in order to more effectively reduce the invalidation caused by schizophrenia and improve patient's social functioning, thus reducing stress levels involved in relapse.

\section{REFERENCES}

Ainsworth, M. D. S., Blehar, M., Waters, E., \& Wall, S. (1978). Patterns of attachment: A psychological study of the strange situation. Hillsdale, NJ: Erlbaum.

Anlı, İ., \& Karslı, T. A. (2010). Perceived parenting style, depression and anxiety levels in a Turkish late-adolescent population. Procedia - Social and Behavioral Sciences, 2(2), 724-727. DOI: 10.1016/j.sbspro.2010.03.091

Baker, C. N., \& Hoerger, M. (2012). Parental child-rearing strategies influence self-regulation, socio-emotional adjustment, and psychopathology in early adulthood: Evidence from a retrospective cohort study. Personality and Individual Differences, 52(7), 800-805. DOI: 10.1016/j.paid.2011.12.034

Barreto Carvalho, C., da Motta, C., Pinto-Gouveia, J., \& Bernardo Peixoto, E. (2014). Emotional, cognitive and behavioral reactions to paranoid symptoms in clinical and nonclinical populations. Clinical Schizophrenia \& Related Psychoses, 1-25. DOI: 10.3371/CSRP.CDCC.061314

Beck, A. T., Ward, C. H., Mendelson, M., Mock, J., \& Erbaugh, J. (1961). An inventory for measuring depression. Archives of General Psychiatry, 4, 561-571. DOI: 10.1001/archpsyc.1961.01710120031004

Bendixen, M., \& Olweus, D. (1999). Measurement of antisocial behaviour in early adolescence and adolescence: Psychometric properties and substantive findings. Criminal Behaviour and Mental Health, 9(4), 323-354. DOI: 10.1002/cbm.330

Benn, L., Harvey, J. E., Gilbert, P., \& Irons, C. (2005). Social rank, interpersonal trust and recall of parental rearing in relation to homesickness. Personality and Individual Differences, 38(8), 1813-1822. DOI: 10.1016/j.paid.2004.11.010

Bifulco, A., Bernazzani, O., Moran, P. M., \& Jacobs, C. (2005). The childhood experience of care and abuse questionnaire (CECA. Q): Validation in a community series. The British Journal of Clinical Psychology / the British Psychological Society, 44(Pt 4), 563-581. DOI: 10.1348/014466505X35344 
Birchwood, M., Gilbert, P., Gilbert, J., Trower, P., Meaden, A., Hay, J., ... Miles, J. N. V. (2004). Interpersonal and role-related schema influence the relationship with the dominant "voice" in schizophrenia: A comparison of three models. Psychological Medicine, 34(8), 1571-1580. DOI: 10.1017/S0033291704002636

Birchwood, M., Trower, P., Brunet, K., Gilbert, P., Iqbal, Z., \& Jackson, C. (2007). Social anxiety and the shame of psychosis: A study in first episode psychosis. Behaviour Research and Therapy, 45(5), 1025-1037. DOI: 10.1016/j.brat.2006.07.011

Bowlby, J. (1969). Attachment and loss. Attachment (2nd ed., Vol. 1, p. 3). New York, NY: Basic Books.

Bowlby, J. (1973). Separation: Anxiety and anger. Attachment and loss (Vol. II, p. 456). New York, NY: Basic Books.

Bowlby, J. (1980). Attachment and loss, volume 3: Loss, sadness and depression (Vol. 3, p. 496). New York, NY: Basic Books.

Campbell, M. L. C., \& Morrison, A. P. (2007). Report experience of paranoia : Comparing the experiences of patients with psychosis and individuals with no psychiatric history, 77, 63-77. DOI: $10.1002 /$ cpp. 510

Chadwick, P., Birchwood, M., \& Trower, P. (1996). Cognitive therapy for delusions, voices and paranoia (p. 232). London: Wiley.

Collins, N. L., \& Feeney, B. C. (2000). A safe haven: An attachment theory perspective on support seeking and caregiving in intimate relationships. Journal of Personality and Social Psychology, 78(6), 1053-1073. DOI: 10.1037/0022-3514.78.6.1053

Craig, W. M. (1998). The relationship among bullying, victimization, depression, anxiety, and aggression in elementary school children. Personality and Individual Differences, DOI: 10.1016/ S0191-8869(97)00145-1

Dagnan, D., Trower, P., \& Gilbert, P. (2002). Measuring vulnerability to threats to self-construction: The self and other scale. Psychology and Psychotherapy, 75(Pt 3), 279-293. DOI: 10.1348/ 147608302320365271

Dixon, A. K. (1998). Ethological strategies for defence in animals and humans: Their role in some psychiatric disorders. The British Journal of Medical Psychology, 71 (Pt 4), 417-445. DOI: 10.1111/j.2044-8341.1998.tb01001.x

Fenigstein, A., \& Vanable, P. (1992). Paranoia and self-consciousness. Journal of Personality and Social Psychology, 62(1), 129-138. DOI: 10.1037/0022-3514.62.1.129

Freeman, D., Garety, P. a, Bebbington, P. E., Smith, B., Rollinson, R., Fowler, D., ... Dunn, G. (2005). Psychological investigation of the structure of paranoia in a non-clinical population. The British Journal of Psychiatry: The Journal of Mental Science, 186, 427-435. DOI: 10.1192/bjp.186.5.427

Gilbert, P. (1992). Human nature and suffering. New York, NY: Lawrence Erlbaum Associates.

Gilbert, P. (1998). Evolutionary psychopathology: Why isn't the mind designed better than it is? The British Journal of Medical Psychology. DOI: 10.1111/j.2044-8341.1998.tb00998.x

Gilbert, P. (2000). Varieties of submissive behavior as forms of social defense: Their evolution and role in depression. In L. Sloman \& P. Gilbert (Eds.), Subordination and defeat (pp. 3-45). Erlbaum.

Gilbert, P. (2001). Evolutionary approaches to psychopathology: The role of natural defences. The Australian and New Zealand Journal of Psychiatry, 35(1), 17-27. DOI: 10.1046/j.14401614.2001.00856.x

Gilbert, P. (2002). Evolutionary approaches to psychopathology and cognitive therapy. Journal of Cognitive Psychotherapy. DOI: 10.1891/jcop.16.3.263.52515

Gilbert, P. (2006). Old and new ideas on the evolution of mind and psychotherapy. Clinical Neuropsychiatry, 3(2), 139-153.
Gilbert, P. (2010). Compassion focused therapy: A special section. International Journal of Cognitive Therapy. DOI: 10.1521/ijct.2010.3.2.95

Gilbert, P., Allan, S., Brough, S., Melley, S., \& Miles, J. N. V. (2002). Relationship of anhedonia and anxiety to social rank, defeat and entrapment. Journal of Affective Disorders, 71(1-3), 141-151. DOI: 10.1016/S0165-0327(01)00392-5

Gilbert, P., Birchwood, M., Gilbert, J., Trower, P., Hay, J., Murray, B., ... Miles, J. N. (2001). An exploration of evolved mental mechanisms for dominant and subordinate behaviour in relation to auditory hallucinations in schizophrenia and critical thoughts in depression. Psychological Medicine, 31(6), 1117-1127. DOI: 10.1017/S0033291701004093

Gilbert, P., Boxall, M., Cheung, M., \& Irons, C. (2005). The relation of paranoid ideation and social anxiety in a mixed clinical population. Clinical Psychology \& Psychotherapy, 12(2), 124-133. DOI: $10.1002 /$ cpp.438

Gilbert, P., Cheung, M. S.-P., Grandfield, T., Campey, F., \& Irons, C. (2003). Recall of threat and submissiveness in childhood: Development of a new scale and its relationship with depression, social comparison and shame. Clinical Psychology E Psychotherapy, 10(2), 108-115. DOI: 10.1002/cpp.359

Hart, J., Gunnar, M., \& Cicchetti, D. (1996). Altered neuroendocrine activity in maltreated children related to symptoms of depression. Development and Psychopathology. DOI: 10.1017/ S0954579400007045

Heider, D., Matschinger, H., Bernert, S., Alonso, J., \& Angermeyer, M. C. (2006). Relationship between parental bonding and mood disorder in six European countries. Psychiatry Research, 143(1), 89-98. DOI: 10.1016/j.psychres.2005.08.015

Irons, C., \& Gilbert, P. (2005). Evolved mechanisms in adolescent anxiety and depression symptoms: The role of the attachment and social rank systems. Journal of Adolescence, 28(3), 325-341. DOI: 10.1016/j.adolescence.2004.07.004

Irons, C., Gilbert, P., Baldwin, M. W., Baccus, J. R., \& Palmer, M. (2006). Parental recall, attachment relating and self-attacking/ self-reassurance: Their relationship with depression. British Journal of Clinical Psychology, 45(3), 297-308. DOI: 10.1348/ $014466505 \times 68230$

Kendall, P. C., Hollon, S. D., Beck, A. T., Hammen, C. L., \& Ingram, R. E. (1987). Issues and recommendations regarding use of the Beck Depression Inventory. Cognitive Therapy and Research, 11(3), 289-299. DOI: 10.1007/BF01186280

Lopes, B. (2010). Paranoia e Ansiedade Social na população não-clínica: Dois fenómenos diferentes?. Universidade de Coimbra.

Manfredi, C., Caselli, G., Rovetto, F., Rebecchi, D., Ruggiero, G. M., Sassaroli, S., \& Spada, M. M. (2011). Temperament and parental styles as predictors of ruminative brooding and worry. Personality and Individual Differences, 50(2), 186-191. DOI: 10.1016/j. paid.2010.09.023

Mikulincer, M., Birnbaum, G., Woddis, D., \& Nachmias, O. (2000). Stress and accessibility of proximity-related thoughts: Exploring the normative and intraindividual components of attachment theory. Journal of Personality and Social Psychology, 78(3), 509-523. DOI: 10.1037/0022-3514.78.3.509

Mills, A., Gilbert, P., Bellew, R., McEwan, K., \& Gale, C. (2007). Paranoid beliefs and self-criticism in students. Clinical Psychology E Psychotherapy, 14(5), 358-364. DOI: 10.1002/cpp.537

Morriss, R. K. (2000). Contextual evaluation of social adversity in the management of depressive disorder. Advances in Psychiatric Treatment, 6(6), 423-431. DOI: 10.1192/apt.6.6.423

Muris, P., Schmidt, H., Lambrichs, R., \& Meesters, C. (2001). Protective and vulnerability factors of depression in normal 
adolescents. Behaviour Research and Therapy, 39(5), 555-565. DOI: 10.1016/S0005-7967(00)00026-7

Parker, G. (1993). Parental rearing style: Examining for links with personality vulnerability factors for depression. Social Psychiatry and Psychiatric Epidemiology, 28(3), 97-100. DOI: 10.1007/ BF00801738

Perris, C. (1988). A theoretical framework for linking the experience of dysfunctional parental rearing attitudes with manifest psychopathology. Acta Psychiatrica Scandinavica. Supplementum, 344, 93-109. Retrieved from http://www.ncbi.nlm.nih.gov/ pubmed/3067534

Richter, J., Richter, G., Eisemann, M., Seering, B., \& Bartsch, M. (1995). Depression, perceived parental rearing and self-acceptance. European Psychiatry: The Journal of the Association of European Psychiatrists, 10(6), 290-296. DOI: 10.1016/0924-9338(96)80310-5

Rutter, M., Dunn, J., Plomin, R., Simonoff, E., Pickles, A., Maughan, B., ... Eaves, L. (1997). Integrating nature and nurture: Implications of person-environment correlations and interactions for developmental psychopathology. Development and Psychopathology, 9(2), 335-364. Retrieved from http:// www.ncbi.nlm.nih.gov/pubmed/9201448

Schore, A. (2000). Attachment and the regulation of the right brain. Attachment \& Human Development, 2(1), 23-47. DOI: $10.1080 / 146167300361309$

Schore, A. (2001). The effects of early relational trauma on right brain development, affect regulation, and infant mental health. Infant Mental Health Journal, 22(818), 201-269. DOI: 10.1002/ 1097-0355(200101/04)22:1<201::AID-IMHJ8>3.0.CO;2-9
Solberg, M. E., \& Olweus, D. (2003). Prevalence estimation of school bullying with the Olweus Bully/Victim Questionnaire. Aggressive Behavior, 29(3), 239-268. DOI: 10.1002/ab.10047

Trower, P., \& Chadwick, P. (1995). Pathways to defense of the self: A theory of two types of paranoia. Clinical Psychology: Science and Practice, 2(3), 263-278. DOI: 10.1111/j.1468-2850.1995. tb00044.x

Trower, P., \& Gilbert, P. (1989). New theoretical conceptions of social anxiety and social phobia. Clinical Psychology Review, 9(1), 19-35. DOI: 10.1016/0272-7358(89)90044-5

Troy, M., \& Sroufe, L. A. (1987). Victimization among preschoolers: Role of attachment relationship history. Journal of the American Academy of Child and Adolescent Psychiatry, 26(2), 166-172. DOI: 10.1097/00004583-198703000-00007

Vaz-Serra, A., \& Pio Abreu, J. (1973). Aferição dos Quadros Clínicos A, Depressivos: I-Ensaio de Aplicação do Inventário Depressivo de Beck uma Amostra Portuguesa de Doentes Deprimidos. Coimbra Médica, 20, 263-264.

Williams, J. M. G., Barnhofer, T., Crane, C., Herman, D., Raes, F., Watkins, E., \& Dalgleish, T. (2007). Autobiographical memory specificity and emotional disorder. Psychological Bulletin, 133(1), 122-148. DOI: 10.1037/0033-2909.133.1.122

Yap, M. B. H., Pilkington, P. D., Ryan, S. M., \& Jorm, A. F. (2014). Parental factors associated with depression and anxiety in young people: A systematic review and meta-analysis. Journal of Affective Disorders, 156, 8-23. DOI: 10.1016/j.jad.2013.11.007 